\title{
Analysis of Selected Aspects of Knowledge Management in the Context of Their Impact on the Quality Level in Metallurgical Enterprises
}

\author{
Rafał Prusak \\ ORCID ID: 0000-0001-9896-7233 \\ Edyta Kardas \\ ORCID ID: 0000-0001-7699-2622 \\ Czestochowa University of Technology, Poland
}

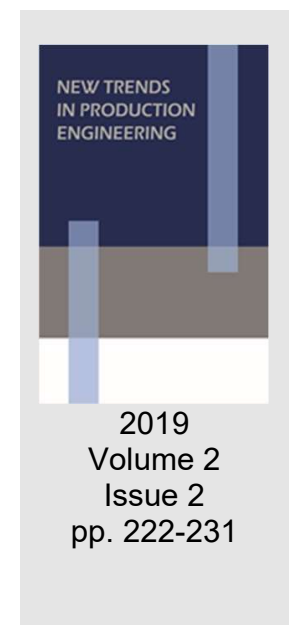

Date of submission to the Editor: 09/2019

Date of acceptance by the Editor: 11/2019

\section{INTRODUCTION}

Quality management is a process that brings specific economic benefits to a company (Cho \& Pucik, 2005) as a result of reducing costs resulting from defects and modifications, related to supervision or stimulation of innovation (Garvin, 1988). In the broad research perspective, apart from the processes usually associated with quality management, the focus of its interest is the improvement of quality and improvement of people, processes, products and the work environment - in particular:

- analysis of the opportunities and benefits of strategic alliances,

- market orientation (per customer) - which can stimulate the multiplicity and effectiveness of innovative practices both in terms of the product and process (Martinez-Costa \& Martinez-Lorente, 2008). Quality management is an important element of the system of increasing the level of meeting the requirements and expectations of customers by improving the overall performance of the company and increasing the amount of knowledge related to the work process and detailed job tasks (Lai, 2003).

- employee empowerment - quality management (especially in the context of TQM) requires strengthening of the employee's position and somehow enforces the concept of complete empowerment of employees (Vouzas \& Psychogios, 2007),

- management of leadership and change - strong leadership is important from the point of view of focusing on quality and innovation and preventing conflicts between functional areas and innovation teams (Govindarajan et al., 2011),

- building teams - engaging all employees in the implementation of processes results in the development of a work productivity culture (Howard and Foster, 1999),

- development of competences and promotion of a learning culture - the resultant knowledge and learning ability can stimulate organizational 
innovation capabilities and enable the building and maintaining of competitive advantages (Martinez-Costa \& Jimenez-Jimenez, 2008)

- shaping a learning culture - enterprises unable to achieve a state of sustainable excellence must continuously acquire knowledge and learn, leading to the development and maintenance of a knowledge creation system (Wang et al., 2007), while strongly emphasizing quality excellence (Senge, 1990). At the same time, learning is one of the desirable products of advanced quality management systems (Barrow, 1993) and additionally, according to the results of some studies, there is a connection between organizational learning and innovation (Hung et al., 2009),

- problem solving and decision-making and as a consequence, among others, acquiring new knowledge as a source of innovation (Nonaka \& Takeuchi, 1995) and promoting productivity (Davenport \& Prusak, 1998).

In this broader analytical perspective, quality management manifests a number of features in common with knowledge management, especially in the context of industrial enterprises. As the research results show, these two processes are closely related to customer orientation (Kaynak, 2003), seek to empower employees and use and develop their potential (Sadikoglu \& Zehir, 2010), focus on continuous process improvement (Oke, 2007), and are related to the development of an open, learning-oriented organizational culture (Kim et al., 2012).

Knowledge management is an area of research and practice that covers a very wide range of elements and relationships existing both between these factors as well as between the knowledge management system and the company's environment. One of the effects of such a broad research perspective is the high diversity of views on what knowledge management is and what are the key elements determining the success of activities undertaken in this area. Some authors perceive knowledge management primarily in the context of a business process aimed at multiplying capital on the basis of intellectual or knowledgebased organizational assets (Davenport \& Prusak, 1998). Others, according to the statement by Nonaki that "knowledge is a dynamic human process of justifying personal belief towards the truth", combine the process of knowledge management with general actions aimed at providing such working conditions in which people will be able to fully use their potential and develop their possessed knowledge in a way that ensures implementation of the strategic goals of the company (Nonaka \& Takeuchi, 1995). The ability to learn and develop as well as transfer knowledge are considered critical issues from the point of view of growth and survival of the organization and building a competitive advantage ( $\mathrm{Hu} \&$ Randel, 2014). As Drucker stated, employee knowledge is the basic capital of the enterprise and the duty of the management is to produce knowledge and inspire activities leading to its creation - creating knowledge requires the systematic, organized addition of new knowledge to the existing one (Drucker, 1993). This process must be assisted by:

- an appropriate organizational solution to overcome barriers to technology transfer, such as: the lack of a social network (Liao \& Xiong, 2011), low level 
of interpersonal relations (Huang et al., 2011) or transfer of data and information, omitting the context in which they arose (Stabryła et al. 2008),

- a well-structured organizational culture that favors appropriate values, attitudes and patterns of actions (Michailova \& Hutchings, 2006), shaping friendly relations between employees (Chang \& Chuang, 2011) as well as fostering teamwork and continuous learning (Dale \& Cooper, 1992),

- a well-functioning communication system (Nonaka \& Takeuchi, 1995),

- a remuneration system rewarding employees actively involved in the processes of creating and sharing knowledge (Garavan et al., 2002),

- an evaluation system that takes into account - with a high priority - issues related to knowledge management (Dale \& Cooper, 1992),

- properly constructed workplaces taking into account appropriate spatial density as well as the number of physical barriers, and facilitating interactions between executors (Kabo, 2018).

Knowledge can be obtained from internal sources (employees, documentation, procedures, systems) as well as external ones (clients and contractors), benchmarking, acquiring know-how or strategic alliances. In the context of internal sources, one should mention the potential difficulties resulting from the fact that knowledge can occur in a public form usually easy to document, transfer and disseminate (Calo, 2008), but also - more valuable - hidden (embedded in the minds of employees, often difficult to identify and transmit) (Lee \& Choi, 2003). Sharing knowledge is one of the key ways to maintain a competitive advantage (Li-Fen, 2010) and may lead to increased productivity (Cummings, 2004), innovation and the development of new business opportunities (Szabó \& Csepregi, 2011). It should be noted, however, that the choice of an appropriate process of sharing knowledge depends on a number of factors, the most important of which can be: the type of preferred knowledge, the frequency of occurrence of such processes and the way of retaining knowledge (individual, collective) (Dixon 2000).

Analysis of the results of research presented in the literature of the subject allows the authors to state that depending on the size of the enterprise, knowledge management systems take different forms and are characterized by different functionality and efficiency (Connelly \& Kelloway 2003). In large enterprises, among others, a better allocation of resources - especially financial resources (Lee, 2016) - and easier support of technological innovations with simultaneous greater difficulties in the implementation of business functions and IT as well as tendencies towards progressive resulting formalization are observed (Leiblein \& Madsen, 2009).

\section{METHODOLOGY OF RESEARCH}

The main objective of the conducted research was an attempt to identify and evaluate selected elements of knowledge management in metallurgical enterprises operating in Poland in the context of improving quality management. The study was conducted on a group of 22 enterprises located in the southern part of Poland, mainly in the Śląskie and Małopolskie Voivodships. The selection 
of research objects was non-random and purpose-based and was based on a few basic criteria: functioning elements of knowledge management must be present in the enterprise; knowledge management must be consciously introduced and placed in the company's operating strategy; employment must be stable for at least two years. The survey was conducted using a questionnaire, which was filled in each time by representatives of top management (each time a group of several people), whose scope of duties and competences were appropriate to answer the questions. Within particular issues, a bipolar scale was used, from -5 to +5 , with extreme values corresponding to the indicated variants (e.g. strategic objectives: -5 : clear, +5 : hidden) and values between intermediate options. The examined criteria were selected based on the concept of a learning organization, according to which the characteristic features of this type of enterprises can be included (Kłak, 2010; Stańczyk-Hugiet, 2005):

- data and information processing leading to the generation of useful knowledge, as well as its effective use and dissemination, combined with the free flow of ideas and new concepts,

- an organizational culture focused on learning and the presentation of different opinions, mutual trust, and team spirit,

- a flat organizational structure, within which there are systems supporting learning (including collective learning), far-reaching delegation of powers,

- continuous development of existing competences and gaining of new ones, participation of all employees in the learning processes and in creating a vision of the future of the enterprise,

- active participation of the management in employee development processes, open borders between superiors and subordinates, a high level of employee motivation,

- internal and external openness, a high level of innovation, experimenting with new methods (taking risks), treating change as a permanent phenomenon.

Taking into consideration the assumptions of a learning organization as part of the questionnaire, the following issues were addressed:

- general assumptions of a knowledge management system (5 questions: 1. strategic goals: clear or hidden from employees, 2. general nature of the company's activities: active or passive, 3. improvement processes: continuous or dependent on needs, 4. knowledge acquisition: purchase or creation, 5. priority type of knowledge: codified or personalized),

- structural and organizational solutions (5 questions: 6. organizational structure: flat or narrow, 7. priority communication channels: formal or informal, 8. information exchange: free or hierarchical, 9. space management: hierarchical or task-based, 10. development of rules: hierarchical or participatory),

- communication and knowledge transfer (3 questions: 11. knowledge transfer: push or pull, 12. priority type of memory: collective or individual, 13. information acquisition: easy or difficult), 
- human resources management (5 questions: 14 . meetings with management: frequent or rare, 15. working conditions: direct control or their formation, 16. human resources development: human capital or sieve model, 17. work mode: individual or group, 18. interpersonal relations: cooperation or competition).

\section{RESULTS AND DISCUSSION}

Figure 1 presents the distribution of responses to individual questions in the questionnaire.

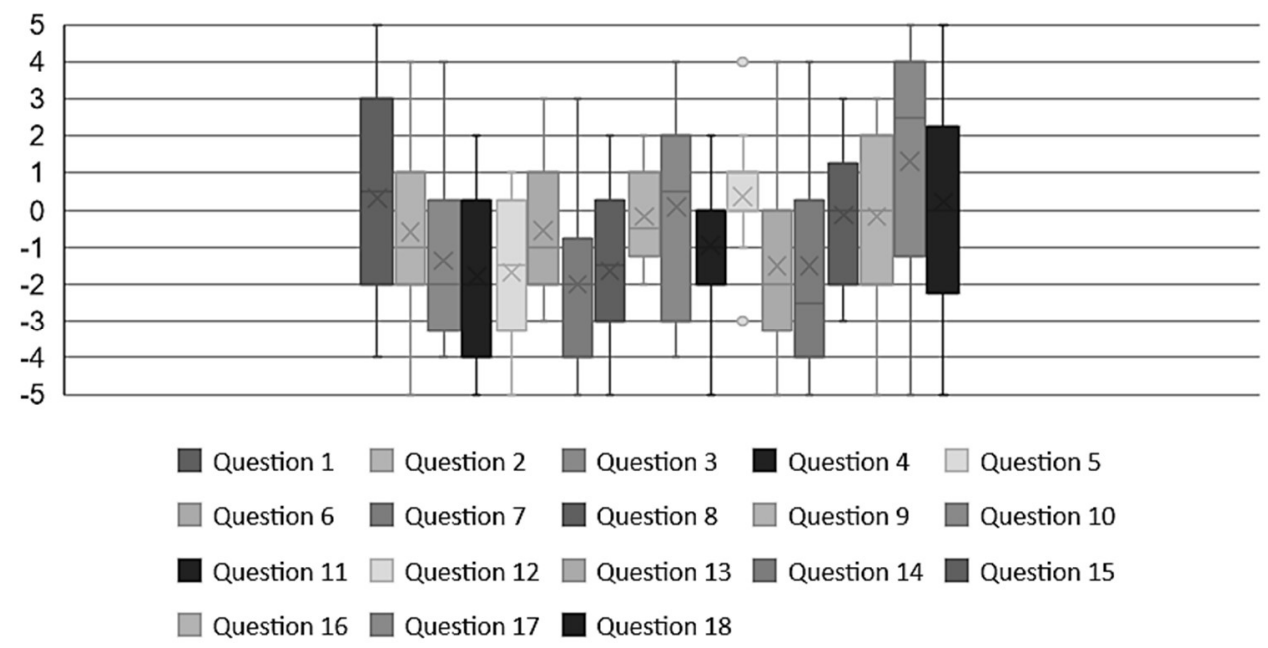

Source: own

Fig. 1 Distribution of responses to individual questions in the questionnaire

The obtained results allow the authors to state that:

- knowledge, technologies, etc. (median -2 and platykurtic data distribution) and codification of knowledge in the form of procedures, technological instructions, databases, etc. (mean -1.68 and more than half of the answers below the value of -1). A slight tendency to leave knowledge about the company's goals to the management was also identified.

- In the context of the applied structural and organizational solutions - in line with general market tendencies - rather flat organizational structures (median 1 , skewed right), a significant advantage of formal solutions (mean and median -2) as well as encouraging employees to exchange information on open information (mean 1.64, platykurtic data distribution) were found.

- In the area of communication and knowledge transfer, there was a clear orientation of existing systems and mechanisms on the ease of obtaining necessary information (median -3 , skewness 0.69 ) as well as top-down control and shaping power development (mean -0.95 , kurtosis -0.11 ). In the context of the type of preferred knowledge retention system, no clear trends were observed (the results indicate a very slight advantage of individual memory).

- As part of human resource management, clear trends were identified related to frequent meetings with managers (mean -1.5 and more than half of the results in the area below -2) and team work mode (mean 1.32, skewness - 
0.75). In other areas, very slight tendencies towards the development of human capital and direct control of processes were identified.

In the surveyed enterprises, an additional analysis was carried out to determine the scale of the effects of introducing the knowledge management system in the context of quality management. The analysis included the number of complaints, the number of incidents, costs of poor quality, punctuality of deliveries, customer service efficiency and the number of lost customers. This study only presents the results for the first of the indicated elements. For the purpose of analysis, the responses of the enterprises were divided into three groups (negative, zero, positive) and - for individual questions - their percentage shares were calculated in the context of the scale of the estimated effects. Table 1 summarizes the obtained results, each time choosing the highest value from among the three groups (the values in bold correspond to a negative answer, the remaining ones are positive (the shares of zero responses were each not very numerous).

Table 1 Summary of the results

\begin{tabular}{|c|c|c|c|c|c|c|c|c|c|c|c|c|c|c|c|c|c|c|}
\hline \multirow[b]{2}{*}{ Effect } & \multicolumn{18}{|c|}{ Question [\%] } \\
\hline & 1 & 2 & 3 & 4 & 5 & 6 & 7 & 8 & 9 & 10 & 11 & 12 & 13 & 14 & 15 & 16 & 17 & 18 \\
\hline none & 14 & 9 & 14 & 14 & 14 & 14 & 18 & 9 & 9 & 9 & 9 & 14 & 18 & 14 & 14 & 9 & 14 & 14 \\
\hline $\begin{array}{l}\text { up to } \\
10 \%\end{array}$ & 9 & 18 & 23 & 9 & 14 & 14 & 23 & 23 & 14 & 14 & 14 & 14 & 14 & 18 & 9 & 14 & 14 & 9 \\
\hline $\begin{array}{l}\text { up to } \\
20 \%\end{array}$ & 18 & 18 & 18 & 18 & 18 & 23 & 14 & 23 & 18 & 14 & 18 & 14 & 18 & 18 & 18 & 18 & 14 & 14 \\
\hline $\begin{array}{l}\text { up to } \\
30 \%\end{array}$ & 9 & 9 & 9 & 9 & 9 & 9 & 9 & 9 & 5 & 9 & 9 & 5 & 9 & 9 & 5 & 5 & 9 & 9 \\
\hline$>30 \%$ & 9 & 9 & 9 & 14 & 9 & 9 & 14 & 9 & 9 & 9 & 9 & 14 & 14 & 9 & 9 & 9 & 9 & 9 \\
\hline
\end{tabular}

Source: own

The analysis of the obtained results allows the authors to state that about $50 \%$ of the surveyed enterprises obtained results in the form of a reduction of the number of complaints at a level of up to $20 \%$ compared to previous periods, and nearly $30 \%$ of the surveyed enterprises reported an improvement of results by over $20 \%$. In the group of enterprises, the best results achieved are as follows:

- $18 \%$ of the studied total population declared the development of the enterprise's goals open (compared to $2 \%$ - declared it classified),

- $18 \%$ declared continuous improvement processes ( $1 \%$ depending on needs),

- $23 \%$ declared the purchase of knowledge (5\% creation),

- $18 \%$ used the codification of knowledge ( $0 \%$ personalization),

- $23 \%$ indicated formal communication channels as priority ( $0 \%$ informal),

- $18 \%$ used a push strategy ( $0 \%$ pull) as part of knowledge transfer,

- $23 \%$ declared easy retrieval of information by employees ( $0 \%$ difficult),

\section{CONCLUSION}

The existence of positive relations between knowledge management and quality in enterprises is confirmed in a number of scientific and research works. Huselid states that the knowledge and skills of employees are more effectively used when they are involved in pro-quality activities (this allows more effective dissemination of their knowledge in the organization) (Huselid, 1995). 
Processes that provide a synergistic combination of data tracking and technology tracking capabilities as well as innovative and developing capabilities of employees must be included in quality management (Malhotra, 1998). Information and data on the past courses of processes should be transformed into knowledge to prevent the reoccurrence of unfavourable phenomena and to intensify beneficial phenomena (Hung et al., 2010).

The conducted research allows the authors to state that knowledge management can be carried out in enterprises, based on many organizational and management solutions that differ from each other. It is more important to choose appropriate instruments, techniques and methods for the specifics of the company's operations than relying on established beliefs or uncritical copying of solutions functioning in other enterprises. Among the number of statements and conclusions from which the results were obtained, attention should be paid to several elements characteristic for the studied group of enterprises. First of all, companies that indicated the priority of knowledge codification and the formalization of information channels combined with the ease of obtaining information achieved better results. The importance of employee participation in project activities was also emphasized, as well as frequent meetings with management, serving both the exchange of knowledge and building appropriate interpersonal relations and mutual trust.

Developing the ability to correctly identify and effectively use knowledge is one of the main challenges for enterprises at the beginning of the $21^{\text {st }}$ century. The estimated potential accumulated within so-called hidden knowledge is still very large, but its disclosure and use requires a well-thought-out system and tools. It is also necessary to effectively and synergistically use relationships and dependencies between the knowledge management system and other systems operating in the enterprise. Activities of this type are difficult, complex and often costly, but they bring with them the possibility of obtaining a number of potential benefits such as unique competitive advantages or increased productivity of people and processes.

\section{REFERENCES}

Barrow, J. W., (1993). Does total quality management equal organizational learning?, Quality Progress, 26(7), 39-43.

Calo, T. J., 2008. Talent Management in the Era of the Aging Workforce: The Critical Role of Knowledge Transfer, Public Personnel Management, 37(4), 403-416. https://doi.org/10.1177/009102600803700403

Chang, H.H., Chuang, S-S, 2011. Social capital and individual motivations on knowledge sharing: Participant involvement as a moderator. Journal Information and Management, 48 (1), 9-18. http://dx.doi.org/10.1016/j.im.2010.11.001

Cho, H., Pucik, V., (2005), Relationship between innovativeness, quality, growth, profitability, and market value, Strategic Management Journal, 26, 555-75.

Connelly, C. E., Kelloway, K. E., 2003, Predictors of employees' perceptions of knowledge sharing cultures, Leadership and Organization Development Journal, 24 (5), 294-301. https://doi.org/10.1108/01437730310485815

Cummings, J. N., 2004. Work Groups, Structural Diversity, and Knowledge Sharing in a Global Organization, Management Science, 50(3), 352-364. 
Dale, B.G., Cooper, C., 1992. Total Quality and Human Resources: An Executive Guide, Oxford, Blackwell.

Davenport, T.H., Prusak, L., 1998. Working Knowledge, Harvard Business School Press, Brighton.

Dixon, N. M., 2000. Common Knowledge: How Companies Thrive by Sharing What They Know, Harvard Business School Press, Boston.

Drucker, P., 1993. Post-Capitalist Society, Harper Business, New York.

Garavan, Th.N., Gunnigle, P., Morley, M., 2000. Contemporary HRD research: a triarchy of theoretical perspectives for HRD, Journal of European Industrial Training, 24 (2/3/4), 466.

Garvin, D., (1988). Managing Quality: The Strategic and Competitive Edge, Free Press, New York.

Govindarajan, V., Kopalle, P. K., Danneels, E., (2011). The Effects of Mainstream and Emerging Customer Orientations on Radical and Disruptive Innovations, Journal of Product Innovation Management, 28(1), 121-132.

Howard, L. W., Foster, S. T., (1999). The influence of human resource practices on empowerment and employee perceptions of management commitment to quality, Journal of Quality Management, 4(1), 5-22.

Hu, L., Randel, A. E., 2014. Knowledge Sharing in Teams: Social Capital, Extrinsic Incentives, and Team Innovation, Group and Organization Management, 39(2), 213-243. https://doi.org/10.1177/1059601114520969

Huang, Q., Davison, R.M., Gu, J., 2011. The impact of trust, guanxi orientation and face on the intention of Chinese employees and managers to engage in peer-to-peer tacit and explicit knowledge sharing, Information Systems Journal, 21, 559-562.

Hung, R. Y., Lien, B., Ya-Hui, McLean, G. N., (2009). Knowledge management initiatives, organizational process alignment, social capital and dynamic capabilities. Advances in Developing Human Resources, 11(3), 320-333.

Hung, R. Y., Lien, B., Fang, S. C., McLean, G. N., (2010). Knowledge as a facilitator for enhancing innovation performance through total quality management. Total Quality Management, 21 (4), 425-438

Houselid, M.;A., (1995). The impact of human resource management practices on turnover, productivity and corporal financial performance. Academy of Management Journal, 38(3), 635-872.

Kabo, Felichism, 2018. The architecture of network collective intelligence: Correlations between social network structure, spatial layout and prestige outcomes in an office. Philosophical Transactions of the Royal Society B: Biological Sciences, 373, 20170238. 10.1098/rstb.2017.0238.

Karani, S. R., Bichanga, W. O., (2012). Effects of Total Quality Management implementation on business performance in service institutions: A case of Kenya Wildlife Services, International Journal of Research Studies in Management, 1(1), 59-76.

Kaynak, H., (2003). The relationship between total quality management practices and their effects on firm performance. Journal of Operations Management, 21(4), 405435.

Kim, D.-Y., Kumar, V., \& Kumar, U., (2012). Relationship between quality management practices and innovation, Journal of Operations Management, 30(4), 295-315.

Lai, K.-H., (2003). Market orientation in quality-oriented organizations and its impact on their performance, International Journal of Production and Economics, 84, 17-34.

Lee, M-Ch., 2016. Knowledge management and innovation management: Best practices in knowledge sharing and knowledge value chain, International Journal of Innovation and Learning, 19, 206. 10.1504/IJIL.2016.074475.

Lee, H., Choi, B., 2003. Knowledge Management Enablers, Processes, and Organizational Performance: An Integrative View and Empirical Examination, Journal of Management Information Systems, 20(1), 179-228. 
Leiblein, M. J., Madsen, T. L., 2009. Unbundling competitive heterogeneity: incentive structures and capability influences on technological innovation. Strategic Management Journal, 30, 711-735. doi:10.1002/smj.746

Liao, K., Xiong, H., 2011. Study on Knowledge Sharing of Community of Practice Based on Social Network Perspective, I-Business, 3, 283-286.

Li-Fen, L., 2006. A learning organization perspective on knowledge sharing behavior and firm innovation, Human Systems Management, 25, 387-404.

Malhotra, D. K., (1998). The impact of interest rate reset period on the bid-offer rates in an interest rate swap contract - an empirical investigation. Journal of Multinational Financial Management, 8 (1), 79-88

Martinez-Costa, M., Jimenez-Jimenez, D., (2008). Are companies that implement TQM better learning organizations? An empirical study, Total Quality Management, 19(11), 1101-1115.

Martinez-Costa, M., Martínez-Lorente, A. R., (2008). Does quality management foster or hinder innovation? An empirical study of Spanish companies. Total Quality Management and Business Excellence, 19(3), 209-221.

Michailova, S., Hutchings, K., 2006. National cultural influences on knowledge sharing: a comparison of China and Russia, Journal of Management Studies, 43, 385.

Nonaka, I. and Takeuchi, H., 1995. The Knowledge-Creating Companies: How Japanese Companies Create the Dynamics of Innovation, Oxford University Press, New York

Oke, A., (2007). Innovation types and innovation management practices in service companies. International Journal of Operations \& Production Management, 27(6), 564-587.

Sadikoglu, E., Zehir, C., (2010). Investigating the effects of innovation and employee performance on the relationship between total quality management practices and firm performance: An empirical study of Turkish firms. International Journal of Production Economics, 127(1), 13-26.

Senge, P. M., (1990). The fifth discipline: The art and purpose of the learning organization. New York: Doubleday/Currency.

Stabryła, A., Cabała, P., Mesjasz, C., Piekarz, H., Woźniak, K., 2008. Metoda kategoryzacji jako narzędzie oceny potencjału wiedzy przedsiębiorstw [in:] Rokita, J. (ed.), Ku nowym paradygmatom nauk o zarządzaniu, Górnośląska Wyższa Szkoła Handlowa im. Wojciecha Korfantego, Katowice.

Szabó, L., Csepregi, A., 2011. Competences Found Important for Knowledge Sharing: Investigation of Middle Managers Working at Medium- and Large-Sized Enterprises, Journal of Knowledge Management, 9, 42-43.

Vouzas, F., Psychogios, A. G., (2007). Assessing managers' awareness of TQM, The TQM Magazine, 19(1), 62-75.

Wang, X., Yang, B., McLean, G. N., (2007). Influence of demographic factors and ownership type upon organizational learning culture in Chinese enterprises. International Journal of Training and Development, 11(3), 154-165. 


\begin{abstract}
.
The review of definitions allows to state that knowledge management in enterprises is a complex, multi-aspect process requiring the implementation of a number of interrelated mechanisms and instruments. Sharing knowledge can increase employee productivity, team performance and the ability to transform diversity into creativity and organizational innovation. Sharing of knowledge in the enterprise should be implemented both in a formal and informal way and be supported by appropriate communication mechanisms, employee exchange programs, job rotation, mentoring relations, techniques Only a well-constructed, implemented and modified system can ensure achieving the intended goals related, among other things, to ensuring the proper functioning of quality assurance mechanisms. and tools for assessing teamwork, a $z$ system promoting creativity and cooperation. The main purpose of the publication is to present the results of research conducted on a sample of 22 enterprises regarding the analysis of the extent of enterprises' use of knowledge and human capital potential to improve the quality management. The research focused mainly on the impact of selected elements of management of knowledge and human capital on the level of employee awareness, as well as the number and type of non-compliance of products. The study used a questionnaire and statistical analysis of data from manufacturing processes.
\end{abstract}

Keywords: quality management, metallurgical enterprise, knowledge management 